\title{
Differences in Philosophical and Psychological Understanding of Subjective Well-Being
}

\author{
Raja Oloan Tumanggor ${ }^{1 *}$ \\ ${ }^{1}$ Faculty of Psychology, Universitas Tarumanagara, Jakarta, Indonesia \\ *Corresponding author. Email: rajat@fpsi.untar.ac.id
}

\begin{abstract}
This study discusses differences in philosophical and psychological understanding of subjective well-being (SWB). SWB is a state of how and why people experience their life positively, both cognitive and affective. This terminology is often interpreted as happiness (life satisfaction). Well-being has been a topic of discussion in philosophy for thousands of years, and the last few decades have become more crowded, especially in the field of positive psychology. When philosophy examines the fundamental understanding of SWB, psychology is more focused on empirical research. The two disciplines of philosophy and psychology have various theories regarding SWB. Although philosophy and psychology have different approaches to SWB, they can collaborate in an interdisciplinary manner to gain a more comprehensive understanding of SWB.
\end{abstract}

\section{Keywords: subjective well-being, philosophical, psychological understanding, differences}

\section{INTRODUCTION}

Since thousands of years ago people have been thinking about what "well-being" means, what makes life good? Scientists try to answer: the most basic thing in a good life is that humans like their lives. Subjective well-being is understood as a cognitive and affective evaluation of his life. This evaluation includes an emotional reaction to each event and a cognitive assessment of life satisfaction. Thus, SWB is a broad concept covering pleasant experiences and a reduction in negative feelings.

In their history philosophers and religious leaders have for thousands of years thought of various characteristics of the "good state" such as love and wisdom. In philosophy the question of SWB as the highest goal of human existence has been discussed in the work of the ancient Greek philosophers. The ancient Greek philosopher Democritus (460-370 BC), for example, was the first to mention a key concept in ethics: eudaimonia as an expression of happiness. Although he was classified as a materialistic atomist, Democritus argued that the human soul became the house of human happiness. Socrates' student Aristippus of Cyrene (300 BC) argued that the human virtue is the ability to obtain pleasure. Then the Athenian philosopher Epicurus (341$270 \mathrm{BC}$ ) taught that the task of philosophy is to find the path to happiness. He declared that all that exist try to avoid suffering. Real pleasure is spiritual in nature such as friendship, knowledge and wisdom [1].

In the 4-2 century BC appeared Stoicism, which had a more assertive attitude about happiness and pleasure in life. Their concept of eudaimonia (happiness) is more static than Aristotle's view. The ultimate goal of human life according to Stoicism is peace. So the Stoics were always known as people who were able to control and control the mind over their emotions. Affective symptoms such as pleasure (hedone), sadness (lupe), desire (epithumia), and fear (phobos) are seen as irrational and incompatible with human nature. So they always pursue perfect virtue called apatheia, the state of the highest good without affective feelings. One of the figures of Stoicism was the Greek philosopher Epictetus (50-138 AD) who emphasized that by obediently people can overcome themselves and build their character. For the Stoicists to be happy in the form of impulsive enthusiasm is viewed negatively, because happiness is never in itself good and an end, but is always associated exclusively with the activities of life that follow. Stoicism believes that happiness is only a companion in one's life and a product of certain personal virtues.

Similar to the view of Stoicism, the Greek philosopher Aristotle (384-322 BC) also stated that people can enjoy life in various ways. In his book Nicomachean Ethics he says that to be happy apart from ethical virtues one must be constant in his life. We also need several external factors such as health, food, protection, healthy children and freedom. Aristotle believed that people can learn to be good and therefore learn how to be happy.

The discussion about SWB continues among philosophers until the middle ages, the enlightenment period until the early 21 st century with all its characters. When philosophers talk about subjective well-being, they try to find the best substantive theory about wellbeing [2]. That is, willing to answer the question: whether the main cause of something is good or bad for 
someone. In a broader context, what makes life good or bad for the people who live it?

According to Stephen M. Campbell, most of the philosophical writings and books that discuss wellbeing currently point to two sides. First, presenting several explanations about well-being so that readers have a fairly clear understanding of the topic. Second, discussing the basic theory of well-being so that the best theory of well-being can be identified. For the first point, the most popular method used to explain wellbeing is to link well-being with topics such as welfare (walfare), personal interest (self-interest), quality of life, progress (flourishing) or a good life. So, anything that contributes to one's well-being is anything that is good or useful to him or her. Anything that has a negative impact on a person's well-being is bad for him. However, it is necessary to distinguish between good for you and good in the absolute sense (good absolutely).

Meanwhile, in psychology, SWB has long been the topic of discussion. One expert who is quite intensively researching SWB is Ed Diener who has written more than 200 articles about SWB. Diener's literature analysis of SWB is contained in a phenomenal article entitled "Subjective Well-being" which is published in the Psychological Bulletin. In this article Diener provides a comprehensive explanation of SWB from a psychological point of view. This great work has even been quoted more than 10,000 times. Diener explains the meaning of SWB, its measurements, and the influence of SWB on health, social contacts, activities and personality [3]. According to Diener, there are three components of SWB, namely life satisfaction, pleasant emotions and unpleasant emotions. Although in everyday use SWB is often synonymous with happiness, the term SWB as a psychological nuance is also defined as a cognitive evaluation of a life filled with happy feelings, without feeling unpleasant. So the SWB model as explained by Diener is actually an extension of the hedonistic well-being construction which was originally adopted from the philosophy of hedonism, which describes the human struggle for happiness and satisfaction while avoiding pain and suffering. However, SWB is not only depicted by the hedonic component, but also all the positive and negative aspects of human life.

However, the problem is what underlies the emergence of various philosophical and psychological theories regarding subjective well-being? Where is the difference between the philosophical and psychological approaches? This study aims to explore various philosophical and psychological theories regarding subjective well-being. Then look for the distinction between these theories and ways of collaborating both philosophical and psychological approaches in order to gain a more comprehensive understanding of subjective well-being.

\section{METHODS}

First of all, the meaning of the variables used is identified, then evaluated critically to obtain a more complete philosophical concept [4]. Thus, the definition of subjective well-being is identified, then its understanding is critically evaluated from a philosophical and psychological perspective. Researchers reviewed the existing literature on subjective well-being from both philosophical and psychological writers. This qualitative study outlines the existing differences, then describes them descriptively and systematically to obtain a more comprehensive understanding of subjective well-being.

\section{RESULT AND DISCUSSION}

\subsection{Philosophical Study of Subjective Well- Being}

The philosophical study of the good life has traditionally been included in the realm of ethics, which is often understood as all aspects of value theory. Ethics in a broad sense is one of the three major branches of philosophy such as metaphysics and epistemology. Sometimes philosophers use ethics in a narrower sense such as morality or moral theory. But ethical theorists often refer to the answer to Socrates' question, "How should people live?" To place SWB research in historical and philosophical contexts it is necessary to understand how philosophers think about the more fundamental notions of 'well-being'. The famous philosophical taxonomy was made by Parfit [5] who divided the theory of well-being into three types, namely hedonistic, desire-fullfilment and an objective list of needs. Meanwhile Heybron [6] developed it into five theories, namely hedonistic theories, desirefullfilment theories, authentic happiness theories, eudaimonistic theories, and list theory. theories).

Hedonic theory identifies well-being with pleasure. In other words, well-being consists of a subjective balance of pleasant and unpleasant experiences. Historical hedonists, for example, are Epicurus and utilitarianism. Hedonists vary in their theoretical formulation. Some prefer to focus on pleasure and pain, others on pleasure and pain, etc. But the central idea is that what is most important to human life is the hedonic quality of individual experiences.

While desire-fulfilment theories identify well-being with the actual satisfaction of personal desires. This theory has an interesting point in that it links the wellbeing of the offender and his motivation. After all, this theory is quite flexible because it can accommodate all the good that people are looking for in their life. And the most important thing is that this theory seems to fit the liberal sensibility of modernity, that is, what is best for me depends on what I care about. But now this theory has raised criticism. One difficulty is that a 
person's desires may conflict with his interests. People can desire anything that is irrelevant to their well-being. According to authentic happiness theories well-being is authentic happiness. That is, being happy is where one's happiness includes both one's living conditions and autonomy. It reflects values that people do have and are not the result of manipulation or oppressive social conditions. So 'happiness' here is something like a subjective well-being, encompassing a global attitude of life satisfaction and positive feelings. The basic idea is that one's happiness should reflect an answer to one's own, towards a life of one's own. When desirefulfilment theories deal with the problem of how irrelevant desires or fulfillment of e-desires that have no effect on my experience can have an affection for my well-being, whereas the authentic happiness perspective produces a demand of experience: only that which gives rise to my happiness can benefit me.

Eudaimonistic theories are influenced by Aristotle's writings which use "eudaimonistic" or "eudaimonic" to describe Aristotle's theory of well-being or views that emphasize perfection or virtue. The definition of eudaimonistic is quite varied, but ethical eudaimonis refers to the antique theory that underlies ethics in the idea of eudaimonia, which is the purpose of life. Some ancient eudaimonists such as the Epicureans denied that eudaimonia was in perfection. The Epicureans agreed with Aristotle that well-being includes our natural fulfillment as human beings, but they believe that we fill our natures with pleasure.

The Aristotelian view identifies well-being with a "well-functioning" which can be said to be living well as a human being: the fulfillment of the human nature. This fulfillment consists, for example, of an exellent life or an admirable activity. Although this is sometimes placed as a full human life. The idea behind the eudaimonic theory is that we develop by fully exercising our human capacities. This is not just a moral issue, although moral virtue is fundamental to wellbeing. So a corporate executive with little concern for others cannot flourish, according to Aristotle, but he will be successful in terms of his own priorities.

Then list theories identify well-being with several lists of goodness such as knowledge, friendship, pleasure, etc. According to this theory, other theories, such as the theory of hedonic, desire, authentic and eudaimonic happiness, do not seem to be able to cover all our intuitions about well-being. The elements of most lists do a lot of good.

When testing well-being theory it is important to distinguish well-being from the broader notion of good life. Even so, we do sometimes use "good life" as a synonym for "well-being". It seems that we always think of life as awesome and worthy of choice. Not only morally good or good for the individual, but also periodically good. Some may deny that it is admirable both for growth and for virtue. The very ethical doctrine states that a good life produces both virtue and wellbeing. The important point here is to see what happens when we do not differentiate carefully the notions of well-being and the good life.

\subsection{Psychological Study of Subjective Well- Being}

Subjective well-being has been a topic of interest to thinkers of all time. No exception Aristotle has written about the "good" life in his Nichomachean Ethics several centuries ago. In fact, in psychology, there is a series of thinkers who review optimal life functions like Maslow with the concept of self-actualization. What is new and important in positive psychology in relation to SWB is that psychological scientists especially Ed Diener developed empirical methods to build a knowledge base of SWB. They created a valid measuring tool for SWB [7].

Many psychologists try to solve the problem of the definition of happiness by looking at SWB, which is an evaluation of one's own life, both cognitive and emotional. Most researchers focus on three components of SWB: positive feelings - the presence of pleasant feelings such as joy, affection, negative feelings feelings of displeasure such as fear, anger and sadness, and personal judgments about satisfaction. Referring to these three components, a happy person is someone who is often happy, rarely sad, and generally satisfied with his life [8].

The psychological study of SWB is an evaluation of one's happiness. Daniel Kahneman, for example, argues that psychology should study objective well-being or happiness, which he defines as a person's positive feelings at a certain moment [9]. However such sensations and feelings are very difficult to measure. Diener instead proposes to learn a person's own assessment of feelings and degrees of happiness. It is easier to measure, for example through surveys and interviews, but also through experiments. Diener argues that a person's judgment of their own happiness is generally more reliable, because in general, people are happy when they think they are happy [10].

Diener argues that there are three components of SWB, namely positive feelings (pleasurable feelings), negative feelings (painful feelings) and life satisfaction [11]. Life satisfaction is how people strike a balance between positive and negative feelings in their life as a whole, and how well their lives live up to their hopes and goals. This is often contrasted with happiness which is seen as a temporary positive feeling situation. Meanwhile, life satisfaction is a cognitive assessment that tends to change only slightly over a long period of time. So SWB is both affective and cognitive, which includes hedonic evaluations led by emotions and feelings, as well as an assessment of people's lives as a whole based on their aspirations and expectations.

Psychological research on SWB tends to use either hedonic or eudaimonic ideas [12]. The hedonic tradition defines SWB or happiness as pleasure and good feelings, and tries to measure its statements either 
through objective or subjective measurement procedures. So the hedonic tradition in psychology is related to the hedonic tradition in philosophy, although its inclusion of life satisfaction as a relevant parameter also leads it to lead to desire-satisfaction approaches.

While the eudaimonic approach argues that happiness or SWB includes objective factors that overcome subjective experiences and attitudes. In particular it includes the actualization of human potential. Therefore, the eudaimonic approach is related to the objective list approach in philosophy, and more specifically to the perfectionist approach. A very influential eudaimonic theory is Martin Seligman's theory of authentic happiness [13]. Seligman argues that a good life is a life that integrates three types of life: pleasant life, dedicated life and meaningful life.

A pleasant life is obtained by having positive feelings about the present, past and future. A dedicated life is a life where dedication and persistent involvement is championed in work, intimate relationships and leisure. In a dedicated activity the attention of the person is perfectly focused on what is useful. Meanwhile, a meaningful life is a life where talents are used to serve something that is believed to be bigger than oneself.

Psychological understanding of SWB can be seen from these three theories: First, the need and goal satisfaction theory argues that SWB is to reduce / reduce tension such as pain and fulfillment of biological and psychological needs will bring people to happiness. Freud's principle of pleasure and Maslow's hierarchical needs model embrace this theory's approach. The degree to which individual needs are met is positive and is seen as satisfying needs. This theory argues that individuals acquire SWB when they move towards ideal situations. Reducing tension and fulfilling biological and psychological desires will bring happiness. The implication is that happiness is achieved after needs and goals are met.

Second, the process or activity theory. This theory can be compared to the happiness model where involvement in activities brings happiness. According to this theory people will be happy if they feel involved in an interesting activity that can test their abilities. So it is important to always participate actively in life. People who have important goals tend to be more energetic, experience positive feelings and feel that life is meaningful. According to the first and second theories, it is argued that SWB will change in line with the existing conditions in people's lives. When people reach their goals or engage in interesting activities, they experience positive well-being. However, other theories hold that there is an element of stability in a person's level of well-being which cannot be explained by the stability in people's living conditions. This theory argues that SWB is influenced by personality dispositions.

Third, the theory of genetic predisposition and personality (genetic and personality predisposition theory). According to this theory, SWB is a cognitive and emotional reaction to life. Some argue that wealth brings the SWB higher only in poor countries. Wealth affects SWB when basic needs are at risk. However, there are also opinions that say, even though the level of basic needs is controlled, income has a significant effect on a nation's SWB. Then the people who are in the richest countries tend to be the happiest people. This is possible because they have more material goods. But it can also be because the wealthiest countries experience a higher level of practice of human rights.

Differences in philosophical and psychological understanding of Subjective Well-being

SWB has become a topic of discussion in various disciplines including philosophy and psychology. In accordance with its character, philosophy always digs deeper into what SWB is. Among philosophers there are various theories that have emerged. The definition of SWB according to philosophy also varies depending on the theory that carries it. Parfit's philosophical taxonomy which consists of three theories (hedonic, wish fulfillment, list of needs), was then developed by Heybron [14] into five theories, namely hedonic, wish fulfillment, authentic happiness, eudaimony, and a list of needs.

While psychology tends to understand SWB in three theories, namely: fulfillment of needs, processes / activities, and genetic/personality predisposition, and SWB has three components, namely: positive, negative feelings, life satisfaction, as well as two approaches: hedonic and eudaimonic. So, from the description above, it can be concluded that the understanding of SWB from a philosophical and psychological perspective needs to be seen from a variety of existing theories. Each theory has its own arguments and rationale. For more details, see the table 1 below.

Table 1 Differences of SWB in philosophy and psychology

\begin{tabular}{ll|}
\hline $\begin{array}{l}\text { Philosophical } \\
\text { understanding }\end{array}$ & $\begin{array}{l}\text { Psychological } \\
\text { understanding }\end{array}$ \\
\hline
\end{tabular}

Three Theories of SWB Three Theories of SWB (Parfit, 1984): hedonism (Diener, 2005): need and theory, desire-fullfilment goal satisfaction theory, theory, objective list process or activiy theory, theory genetic and personality theory.

Five theories of SWB Three components of (Heybron, 2008): SWB (Diener \& Lucas, hedonism theory, desire- 1999): positive feeling, fullfilment theory, negative feeling, life authentic happiness satisfaction. theory, eudaimonic theories, need theory

Two approaches of SWB (Bruni \& Porta, 2005): Hedonic, eudaimonic

The difference between philosophical and psychological approaches with each of the three theories regarding subjective well-being has an influence on the 
understanding of the concept of subjective well-being. When compared to the two approaches, it appears that the philosophical approach to SWB is theoretical idealistic, while the psychological approach is more practical empirical. This means that philosophy wrestles in the fundamental realm, looking for the basics of SWB. Meanwhile, psychology tries to explore SWB in human empirical experience, complete with all measurement processes. If you pay closer attention there are similarities in ideas in understanding SWB from a philosophical and psychological perspective, for example in a philosophical view there is a theory of the fulfillment of needs, while in a psychological view it is called a theory of meeting needs and goals. Then the eudaimonic theory from the philosophical view of Heybron's version was adopted by psychology in making an understanding approach to SWB.

Which one should be chosen from these two approaches in order to obtain a more complete and comprehensive understanding of subjective well-being? In accordance with the basic nature of philosophy which always seeks the basic meaning and fundamentals of everything, the three theories from a philosophical perspective regarding SWB are needed to further enrich the understanding of SWB from a psychological perspective. Philosophy knows no end point. Philosophy always asks and continues to explore the deepest meaning of SWB. And that is needed to enrich and deepen the discussion about SWB. Meanwhile, an empirical approach from psychology can make philosophical understanding more concrete and real. So, exploring differences in the understanding of philosophy and psychology on SWB does not want to separate the two disciplines but instead strengthen the two so that an interdisciplinary collaboration can be established.

\section{CONCLUSION}

Subjective Well-Being (SWB) has been the subject of philosophical discussion for a long time. From these discussions, there are three main schools of theory that are quite prominent, namely hedonic theory, desirefulfilment theory and objective list theory. Meanwhile, according to the psychological perspective SWB has two main components, namely affective and cognitive, such as feelings of pleasure and life satisfaction. In a philosophical perspective, this feeling of pleasure and satisfaction is included in the realm of hedonic theory. Meanwhile, the cognitive component of SWB from a psychological perspective falls within the realm of needs fulfillment theory from a philosophical perspective. Although there are differences in philosophical and psychological approaches to SWB, there are also similarities in ideas. This can be understood because the psychological understanding of SWB cannot be separated from the ideas and philosophical reflections on SWB that have been going on for thousands of years. What is clear is that a philosophical approach can help us to understand the psychological notion of SWB, while empirical experience which forms the basis of the analysis of the psychological approach can make philosophical reflection more grounded.

Because this study is only in the form of a theoretical study of differences in understanding of SWB from a philosophical and psychological perspective, the researchers suggest that in further studies it is necessary to conduct research on the relevance of empirical psychological research on SWB to the philosophical theory of SWB. This means, the extent to which the results of psychological research on SWB have an influence on understanding the philosophy of SWB. Do the results of an empirical study of psychology on SWB support the philosophical concept of SWB or not.

\section{ACKNOWLEDGMENT}

I thank the Directorate of Research and Community Service (DPPM) Universitas Tarumanagara Jakarta which has facilitated me to conduct this research.

\section{REFERENCES}

[1] Drakulic, A.M. (2012) A Phenomenological Perspective on Subjective Well-being: From Myth to Science. Psychiatria Danubina 24, no. 1, 31-37.

[2] Campbell, S.M. (2016). "The Concept of Wellbeing" in Guy Fletcher (ed) The Routledge Handbook of Philosophy of Well-Being.

[3] Diener, E. (1984). Subjective Well-being. Psychological Bulletin 95 no. 3, 542-575.

[4] Bakker, A., \& Zubair, A. C. (2012). Metodologi Penelitian Filsafat, Yogyakarta: Kanisius.

[5] Parfit, D. (1984). Reasons and Persons, Oxford University Press.

[6] Haybron, D.M. (2008). Philosophy and the Science of Subjective Well-being, in: Michael Eid \& Randy J. Larsen (eds) The Science of Subjective Well-being. New York. London: The Guilford Press, 2008, 17-43.

[7] Larsen, R.J. \& Eid, M. (2008). Ed Diener and the Science of Subjective of Well-Being. In The Science of Subjective of Well-Being edited by R.J. Larsen \& M. Eid, New York London: The Guilford Press. 
[8] Biswas-Diener, R.; Diener, Ed. \& Tamir, M. (2004). The Psychology of Subjective Well-being. Daedalus 133, 18-25.

[9] Kahneman, D. (1999) Objective happiness. In Well-being: Foundation of hedonic psychology edited by D. Kahneman, E. Diener \& N. Schwarz, New York: Russell Sage Foundation Press.

[10] Brey, Philip (2012). Well-being in Philosophy, Psychology and Economic. In: Brey, P., Briggle, A. \& Spence, E. (Eds.), The Good Life in a Technological Age. Routledge, 15-34.

[11] Diener, E., \& Lucas, R.E. (1999) Subjective Well-being. The Science of Happiness and Life Satisfaction.

[12] Bruni, L. \& Porta, L.P. (2005). Economic and Happiness, Oxford University Press.

[13] Seligman, M.E.P. (2002). Authentic Happiness: Using the New Positive Psychology to Realize Your Potential for Lasting Fulfillment. New York: Free Press.

[14] Diener, E., Lucas, R. E., dan Oishi, S. (2005). Subjective Well-Being: The Science of Happiness and Life Satisfaction. Handbook of Positive Psychology.NC: Oxford University Press. 